\title{
Assessment of Adipocyte Differentiation and Maturation-related Gene Expression in the Epididymal Fat of Estrogen Receptor a Knockout (ERaKO) Mouse during Postnatal Development Period
}

\author{
Yong-Pil Cheon', CheMyong Ko ${ }^{2}$, and ${ }^{\dagger} \mathrm{Ki}-\mathrm{Ho} \mathrm{Lee}^{3}$ \\ 'Division of Development and Physiology, Department of Biotechnology, CDPR, Institute for Basic Science, Sungshin \\ Women University, Seoul, 02844 Korea \\ ${ }^{2}$ Dept. of Comparative Biosciences, College of Veterinary Medicine, University of Illinois at Urbana-Champaign, \\ Urbana, IL 61802, USA \\ ${ }^{3}$ Dep. of Biochemistry and Molecular Biology, College of Medicine, Eulji University, Daejeon 34824, Korea
}

Received: November 7, 2020

Revised: November 17, 2020

Accepted: November 28, 2020

${ }^{+}$Corresponding author

Ki-Ho Lee

Dep. of Biochemistry and Molecular

Biology, Eulji University, Daejeon 34824,

Korea.

Tel: +82-42-259-1643

Fax: +82-42-259-1649

E-mail: kiholee@eulji.ac.kr

Copyright $\odot 2020$ The Korean Society of Developmental Biology.

This is an Open Access article distributed under the terms of the Creative Commons Attribution Non-Commercial License (http://creativecommons.org/licenses/ by-nc/4.0/) which permits unrestricted non-commercial use, distribution, and reproduction in any medium, provided the original work is properly cited.

ORCID

Yong-Pil Cheon

https://orcid.org/0000-0002-8497-9257 CheMyong Ko

https://orcid.org/0000-0002-0963-3731 Ki-Ho Lee

https://orcid.org/0000-0002-3495-5126

Conflict of interests

The authors declare no potential conflict of interest.

\section{Abstract}

The absence of functional estrogen receptor a (Esr1) results in an overgrowth of the epididymal fat, as observed in estrogen receptor a knockout (ERaKO) mouse. The present research was aimed to evaluate expression of various molecules associated with adipocyte differentiation and maturation in the epididymal fat of ERaKO mouse at several postnatal ages by using quantitative real-time polymerase chain reaction. The highest transcript levels of all molecules were detected at 12 months of postnatal age, except leptin which the mRNA level was increased at 5 months of age and was unchanged until 12 months of age. The expression levels of CCAAT enhancer binding protein (Cebp) alpha, androgen receptor, and lipoprotein lipase were decreased at 5 months of age but increased at about 8 months of age. The mRNA levels of Cebp gamma and sterol regulatory element binding transcription factor 1 remained steady until 8 months of age. Continuous increases of transcript levels during postnatal period were found in Cebp beta, estrogen receptor (ER) beta, fatty acid binding protein 4 , and delta like non-canonical Notch ligand 1 . The increases of peroxisome proliferator-activated receptor gamma and adiponectin mRNA levels were detected as early as 8 months of age. The levels of fatty acid synthase and resistin transcript at 5 and 8 months of age were lower than that at 2 months of age. These findings show the aberrant expression patterns of genes related to adipocyte differentiation and maturation in the postnatal epididymal fat pad by the disruption of ER alpha function.

Keywords: Estrogen receptor a knockout (ERaKO) mouse, Epididymal fat, Postnatal development, Real-time polymerase chain reaction (PCR), Differentiation, Maturation 
Acknowledgements

This research was supported by Basic

Science Research Program through the

National Research Foundation of Korea

(NRF) funded by the Ministry of Education

(2017R1D1A1B03030209).

\section{Authors' contributions}

Conceptualization:Lee KH.

Data curation: Lee KH.

Formal analysis: Lee $\mathrm{KH}$.

Methodology: Cheon YP, Ko CM, Lee KH.

Investigation: Lee $\mathrm{KH}$.

Writing - original draft: Lee $\mathrm{KH}$.

Writing - review \& editing: Cheon YP, Lee KH.

\section{Ethics approval}

All procedures were carried out in accordance with the guidelines for the care and use of laboratory animals of National Research Council in Korea.

\section{INTRODUCTION}

The continuous growth and expansion in size during the lifetime is a characteristic of fat tissue, unlike other tissues having limited developmental capacity (Hausman et al., 2001). The epididymal fat is a gonadal fat belonging to interperitoneal white adipose tissue, most of the epididymal fat is present near the head of epididymis (Berry et al., 2013; Lee, 2020). Based on the location and histochemical characteristics, the epididymal fat pad is divided into distal, proximal, and tail epididymal fat (Tirard et al., 2007; Lee, 2020). The epididymal fat tissue contains several cell types, including mature adipocyte, preadipocytes, immune cell, and endothelial cell (Cleary et al., 1977). The lipid-filled adipocyte in the mouse epididymal fat begins to appear as early as 7 days of postnatal age (Han et al., 2011). In the rat, the active proliferation of adipocyte and nonadipocyte cells in the epididymal fat tissue is observed from 12 to 35 days of age, and further remarkable increase of non-adipocyte cells in the number is found from 35 to 70 days of age (Cleary et al., 1977). In addition, the number and size of lipid-filled adipocytes is also rapidly increased from 35 to 70 days of age, even though changes of cells in epididymal fat tissue remain in the steady level or is slightly occurred after 70 days of age (Cleary et al., 1977), indicating dynamical functional and morphological changes in the epididymal fat cells during postnatal period.

The development and growth of fat tissue are influenced by various factors, including age, nutrition, and hormones. Knittle \& Hirsch (1968) have demonstrated that nutritional difference during early postnatal period gives an effect on long-lasting changes in cell size and number of the rat epididymal fat pad. Not only the wet weight but also a relative weight to body weight of the epididymal fat are continuously increased during postnatal period (Cleary et al., 1977). The changes of fat cell number and size by hormonal regulation have been demonstrated by a number of researches (References in Hausman et al., 2001). In addition, the effect of sex steroid hormones, testosterone and estrogen, on the development of the epididymal fat has been suggested. Indeed, the presence of a relatively high concentration of androgen receptor (AR) in the epididymal fat has been demonstrated (Dieudonne et al., 1995). Moreover, the existence of estrogen receptor (ER) in the epididymal fat has been revealed (Gray \& Wade, 1980), and the expressional regulation of ER $\alpha$ in the epididymal fat by diet has been shown (Metz et al., 2016). Other researches have found that the effect of such hormonal factors on the proliferation and differentiation of epididymal adipocyte is likely exerted through the expression regulation of various transcription factors, including CCAAT/enhancer binding proteins, insulin-like growth factor 1, peroxisome proliferator-activated receptor gamma (Dieudonne et al., 1995; References in Hausman et al., 2001). These observations suggest that estrogen could give an influence on the development of the epididymal fat tissue by regulating the expression of adipogenesis-associated molecules.

The estrogen receptor $\alpha$ knockout (ER $\alpha \mathrm{KO}$ ) mouse has a genetically non-functional $\mathrm{ER} \alpha$ and is useful to examine the in vivo function of $\mathrm{ER} \alpha$. Of various abnormal characteristics found in the $\mathrm{ER} \alpha \mathrm{KO}$ mouse, it is notable that $\mathrm{ER} \alpha \mathrm{KO}$ mouse has more white adipose tissue than wild type (WT) in both male and female (Heine et al., 2000). In male ER $\alpha$ KO mouse, the epididymal fat is already heavier than WT mouse at 30 days of postnatal age, and the weight difference of the epididymal fat between WT and $\mathrm{ER} \alpha \mathrm{KO}$ mice become greater with age (Heine et al., 2000). The heavier epididymal fat tissue in $\mathrm{ER} \alpha \mathrm{KO}$ mouse is likely due to increases of adipocyte size and number (Heine et al., 2000). Because the differentiation and proliferation of adipocyte are regulated by a combined action of anti- and pro-adipogenic transcription factors (Mareno-Navarrete \& Fernández-Real, 2012), it is reasonable to consider that a lack of functional ER $\alpha$ would result 
in expressional de-regulation of such transcription factors-associated with the development of epididymal fat during postnatal period.

Thus, the present research has attempted to determine expression patterns of several transcription factors promoting adipogenesis in the $\mathrm{ER} \alpha \mathrm{KO}$ mouse epididymal fat at different postnatal ages. In addition, expression of $\mathrm{AR}$ and $\mathrm{ER} \beta$ at postnatal ages has been examined. Moreover, transcriptional expression of adipocyte function-related molecules and secretory hormones in the epididymal fat during postnatal period has been studied.

\section{MATERIALS AND METHODS}

\section{Experimental animals and tissue collection}

The homozygote ER $\alpha$ KO male mice around 2 ( $n=4), 5 \quad(n=4), 8$ (n=3), and 12 (n=3) months of postnatal ages were obtained from a colony maintained in Sungshin Women's University. The $\mathrm{ER} \alpha \mathrm{KO}$ mice were produced as described in a previous report (Gieske et al., 2008).

The euthanization of mouse was performed by over-exposure to $\mathrm{CO}_{2}$ in a chamber, and a small incision was made at lower abdominal cavity of the mouse. The male reproductive tract, including testis, epididymis, and epididymal fat, was exposed through the incision and placed in a cold phosphate buffered saline (PBS) solution. The epididymal fat pad was carefully dissected and separated out from the rest. The fat pad was quickly rinsed in fresh cold PBS solution and placed in liquid nitrogen. The tissue was stored in $-80^{\circ} \mathrm{C}$ until used for total RNA extraction.

\section{Extraction of total RNA and analysis of gene expression}

The frozen epididymal fat was used for total RNA isolation by a standard extraction method with Trizol reagent (Molecular Research Center, Cincinnati, OH, USA). Briefly, the epididymal fat tissue was quickly homogenized in Trizol solution, and total RNA was isolated and precipitated by a sequential supplement of chloroform and isopropanol. An amount of total RNA resuspended in DEPC- $\mathrm{dH}_{2} \mathrm{O}$ was quantitated by NanoDrop Lite spectrophotometer (Thermo Scientific, Massachusetts, MA, USA).

The generation of complementary DNA (cDNA) from total RNA was carried out by using iScrip ${ }^{\mathrm{TM}}$ Reverse transcription Supermix for reverse transcription (RT)-qPCR (Bio-Rad Laboratories, Hercules, CA, USA), $1 \mu \mathrm{g}$ of total RNA, and nuclease-free $\mathrm{dH}_{2} \mathrm{O}$ to make a final volume of $20 \mu \mathrm{L}$. The RT reaction was executed at $25^{\circ} \mathrm{C}$ for $5 \mathrm{~min}, 46^{\circ} \mathrm{C}$ for $20 \mathrm{~min}$, and $95^{\circ} \mathrm{C}$ for 1 $\min$.

A mixture of $1 \mu \mathrm{L}$ of $\mathrm{cDNA}, 7 \mu \mathrm{L}$ of $\mathrm{iQ}^{\mathrm{TM}} \mathrm{SYBR}^{\circledR}$ Green Supermix (Bio-Rad Laboratories), $10 \mathrm{pmol}$ of individual primer, and nuclease-free $\mathrm{dH}_{2} \mathrm{O}$ to adjust a final volume of $25 \mu \mathrm{L}$ was subjected for quantitative real-time PCR analysis. The oligonucleotide primers were designed by Primer 3 software (https://bioinfo.ut.ee/primer3: Kõressaar et al., 2018), and sequences and detailed information of the primers are listed in Table 1. The examined molecules were CCAAT enhancer binding protein, alpha (Cebpa), CCAAT enhancer binding protein, beta (Cebpb), CCAAT enhancer binding protein, gamma $(C e b p g)$, sterol regulatory element binding transcription factor 1 (Srebf1), $A r$, ER, alpha (Esr1), ER, beta (Esr2), peroxisome proliferator-activated receptor, gamma (Pparg), fatty acid binding protein 4 (Fabp4), delta like non-canonical Notch ligand 1 (Dlk1), fatty acid synthase (Fasn), lipoprotein lipase (Lpl), leptin (Lep), adiponectin (Adipoq), and resistin (Retn). The 18s ribosomal RNA (Rn18s) was included as a PCR internal control. The PCR was performed in the condition of a pre-denaturation step at $95^{\circ} \mathrm{C}$ for $5 \mathrm{~min}$, cycles of a denaturation step at $95^{\circ} \mathrm{C}$ for $30 \mathrm{sec}$, an annealing step at $\mathrm{Tm}$ for $30 \mathrm{sec}$, and an extension step at $72^{\circ} \mathrm{C}$ for $30 \mathrm{sec}$, and an extra 
Table 1. Primer information for real-time PCR analysis

\begin{tabular}{|c|c|c|c|}
\hline Gene & Sequence $\left(5^{\prime} \rightarrow 3^{\prime}\right)$ & $\mathrm{T}_{\mathrm{m}}\left({ }^{\circ} \mathrm{C}\right)$ & PCR product (bps) \\
\hline $\begin{array}{l}\text { Cebpa } \\
\text { (NM_001287523.1) }\end{array}$ & $\begin{array}{l}\text { (F) AGAAGTCGGTGGACAAGAAC } \\
\text { (R) CTTGACCAAGGAGCTCTCAG }\end{array}$ & 52 & 233 \\
\hline $\begin{array}{l}\text { Cebph } \\
\text { (NM_009883.4) }\end{array}$ & $\begin{array}{l}\text { (F) ATGCAATCCGGATCAAACGTG } \\
\text { (R) CAACCCCGCAGGAACATCTTTA }\end{array}$ & 60 & 113 \\
\hline $\begin{array}{l}\text { Cebpg } \\
\text { (NM_009884.3) }\end{array}$ & $\begin{array}{l}\text { (F) ACCCATGGATCGGAATAGTG } \\
\text { (R) GCTTCCAACCGTTCATTCTC }\end{array}$ & 55 & 150 \\
\hline $\begin{array}{l}\text { Srebf1 } \\
\text { (NM_011480.3) }\end{array}$ & $\begin{array}{l}\text { (F) AGGTCACCGTTTCTTTGTGG } \\
\text { (R) TCCAAGGGCATCTGAGAACT }\end{array}$ & 55 & 208 \\
\hline $\begin{array}{l}\text { Ar } \\
\left(\mathrm{NM} \_013476.4\right)\end{array}$ & $\begin{array}{l}\text { (F) TGTCAAAAGTGAAATGGGACC } \\
\text { (R) TGGTACTGTCCAAACGCATGT }\end{array}$ & 55 & 74 \\
\hline $\begin{array}{l}\text { Esr1 } \\
\text { (AB560752.1) }\end{array}$ & $\begin{array}{l}\text { (F) GCCTCTGGCTACCATTATGG } \\
\text { (R) CATCTCTCTGACGCTTGTGC }\end{array}$ & 55 & 244 \\
\hline $\begin{array}{l}\text { Esr2 } \\
\text { (U81451.1) }\end{array}$ & $\begin{array}{l}\text { (F) GTCAGGGTGGTTGGGTTGTGG } \\
\text { (R) ATCGCGTCACTTTCCTTTTCC }\end{array}$ & 55 & 203 \\
\hline $\begin{array}{l}\text { Pparg } \\
\text { (U01841.1) }\end{array}$ & $\begin{array}{l}\text { (F) GATTCATGACCAGGGAGTTC } \\
\text { (R) GACTCTGGGTGATTCAGCTT }\end{array}$ & 60 & 247 \\
\hline $\begin{array}{l}\text { Fabp4 } \\
\text { (NM_024406.3) }\end{array}$ & $\begin{array}{l}\text { (F) CAAGCCCAACATGATCATCAGC } \\
\text { (R) CACGCCCAGTTTGAAGGAAATC }\end{array}$ & 60 & 97 \\
\hline $\begin{array}{l}\text { Dlk1 } \\
\text { (NM_010052.5) }\end{array}$ & $\begin{array}{l}\text { (F) GGCCATCGTCTTTCTCAACA } \\
\text { (R) CTCCTCATCACCAGCCTCCT }\end{array}$ & 60 & 181 \\
\hline $\begin{array}{l}\text { Fasn } \\
\text { (NM_011480.3) }\end{array}$ & $\begin{array}{l}\text { (F) GTGTGGACATGGTCACAGATG } \\
\text { (R) GACCGCTTGGGTAATCCATA }\end{array}$ & 60 & 67 \\
\hline $\begin{array}{l}\text { Lpl } \\
\text { (NM_008509.2) }\end{array}$ & $\begin{array}{l}\text { (F) TCAGAGCCAAGAGAAGCAGCA } \\
\text { (R) TTGTGTTGCTTGCCATCCTCA }\end{array}$ & 60 & 118 \\
\hline $\begin{array}{l}\text { Lep } \\
\text { (NM_008493.3) }\end{array}$ & $\begin{array}{l}\text { (F) TTCACACACGCAGTCGGTAT } \\
\text { (R) TCATTGGCTATCTGCAGCAC }\end{array}$ & 55 & 165 \\
\hline $\begin{array}{l}\text { Adipoq } \\
\text { (NM_009605.5) }\end{array}$ & $\begin{array}{l}\text { (F) AGGCCGTTCTCTTCACCTACG } \\
\text { (R) GACTTGGTCTCCCACCTCCAGA }\end{array}$ & 62 & 95 \\
\hline $\begin{array}{l}\text { Retn } \\
\text { (NM_022984.3) }\end{array}$ & $\begin{array}{l}\text { (F) TTCCTTGTCCCTGAACTGCT } \\
\text { (R) TCAAGACTGCTGTGCCTTCT }\end{array}$ & 55 & 187 \\
\hline $\begin{array}{l}\text { Rn18s } \\
\text { (NM_03278.3) }\end{array}$ & $\begin{array}{l}\text { (F) ACTCAACACGGGAAACCTCA } \\
\text { (R) AACCAGACAAATCGCTCCAC }\end{array}$ & 55 & 123 \\
\hline
\end{tabular}

PCR, polymerase chain reaction; Cebpa, CCAAT enhancer binding protein, alpha; Cebpb, CCAAT enhancer binding protein, beta; Cebpg, CCAAT enhancer binding protein, gamma; Srebf1, sterol regulatory element binding transcription factor 1 ; Ar, androgen receptor; Esr1, estrogen receptor, alpha; Esr2, estrogen receptor, beta; Pparg, peroxisome proliferator-activated receptor, gamma; Fabp4, fatty acid binding protein 4; DIk1, delta like non-canonical Notch ligand 1; Fasn, fatty acid synthase; Lpl, lipoprotein lipase; Lep, leptin; Adipoq, adiponectin; Retn, resistin; Rn18s, 18s ribosomal RNA.

extension step at $72^{\circ} \mathrm{C}$ for $10 \mathrm{~min}$. The size of PCR product was confirmed by $1.2 \%$ agarose gel electrophoresis.

\section{Statistical analysis and data presentation}

The transcript level of target gene at a specific postnatal age was normalized to that of Rn18s transcript level, and the relative expression ratios of target gene among different postnatal ages were calculated by $2^{-\Delta \Delta \mathrm{Ct}}$ method (Livak \& Schmittgen, 2001). A mean and standard error of target gene at a given age was obtained from separately triplicated RT reactions and PCRs. The data were expressed in a relative ratio of target gene at each postnatal age against its of 2 months of age. Statistical differences of expression level of target gene among different postnatal ages were determined by one-way ANOVA, followed by Duncan's test if a significance was present. When a probability was less than 0.05 , it was considered that a statistical significance was present between those age groups. 


\section{RESULTS}

\section{Postnatal expression patterns of Cebpa, Cebpb, and Cebpg in the epididymal fat pad of ER $\alpha$ KO mouse}

Expression patterns of Cebp family are shown in Fig. 1. The level of Cebpa transcript at 5 months of age was significantly lower than that at 2 months of age, but the expression level of Cebpa at 8 months of age was not different with that at 2 months of age (Fig. 1A). The dramatic increase of Cebpa mRNA level was detected at 12 months of age (Fig. 1A).

A significant increase of Cebpb transcript level was detected at 5 months of age, compared with that at 2 months of age (Fig. 1B). Expression level of Cebpb in the ER $\alpha$ KO epididymal fat was further increased at 8 months of age, followed by about 87 times surge of Cebp $b$ mRNA level at 12 months of age (Fig. 1B). There was no statistical change of Cebpg transcript level in the $\mathrm{ER} \alpha \mathrm{KO}$ epididymal fat from 2 months of age to 8 months of age (Fig. 1C). However, over 50 folds increase of Cebpg was observed at 12 months of age (Fig. 1C).

\section{Postnatal expression patterns of Srebp1, Ar, Esr1, and Esr2 in the epididymal fat pad of ER $\alpha$ KO mouse}

A significant change of Srebp1 transcript level in the $\mathrm{ER} \alpha \mathrm{KO}$ epididymal fat was only observed at 12 months of age, but not at other ages (Fig. 2A). The level of $A r$ mRNA at 5 months of age was significantly decreased at 5 months of age, compared with that at 2 months of age (Fig. 2B). But, the transcript level of $A r$ at 8 months of age was greatly higher than those at 2 and 5 months of age (Fig. 2B). The highest level of $A r$ transcript was found in the $\mathrm{ER} \alpha \mathrm{KO}$ epididymal fat at 12 months of age (Fig. 2B).

There was no Esr1 transcript detected at all experimental age groups, as expected (no data shown). A significant increase of $E s r 2$ was observed at 5 months of age, followed by an additional rise of Esr 2 transcript level in the $\mathrm{ER} \alpha \mathrm{KO}$ epididymal fat at 8 months of age (Fig. 2C). Like other molecules, the highest level of Esr 2 in the $\mathrm{ER} \alpha \mathrm{KO}$ epididymal fat was detected at 12 months of age (Fig. 2C).

\section{Postnatal expression patterns of Pparg, Fabp4, and DIk1 in the epididymal fat pad of ER $\alpha$ KO mouse}

The mRNA level of Pparg in the ER $\alpha$ KO epididymal fat at 5 months of age was not

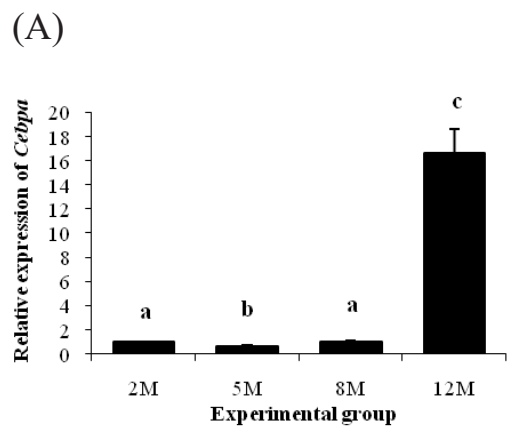

(B)

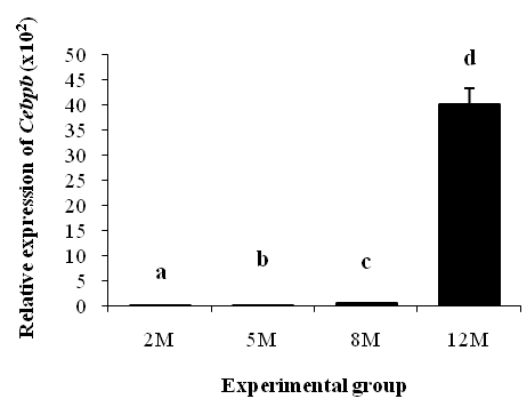

(C)

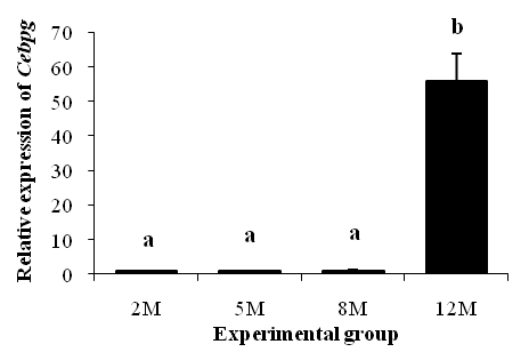

Fig. 1. Expression patterns of Cebpa, Cebpb, and Cebpg in the epididymal fat tissue of ERaKO mouse at different postnatal ages. The transcript levels of Cebpa (A), Cebpb (B), and Cebpg (C) genes were normalized against its of $R n 18 \mathrm{~s}$, and relative expression ratios were calculated by $2^{-\Delta \Lambda C t}$ method (Livak \& Schmittgen, 2001 ). Each value represents the mean \pm SEM of three to five mice. Lower cases on bars indicate statistical significances among experimental groups at $p<0.05$. M, months of postnatal age; Cebpa, CCAAT enhancer binding protein, alpha; Cebpb, CCAAT enhancer binding protein, beta; Cebpg, CCAAT enhancer binding protein, gamma; 18s ribosomal RNA. ERaKO, estrogen receptor $\alpha$ knockout. 
(A)

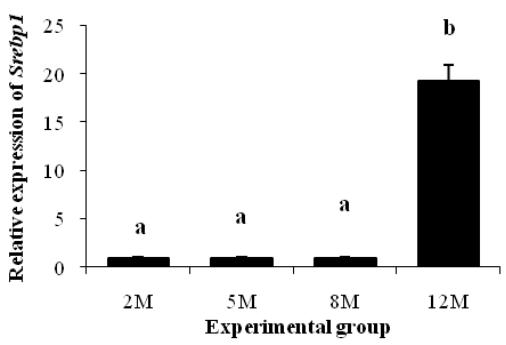

(B)

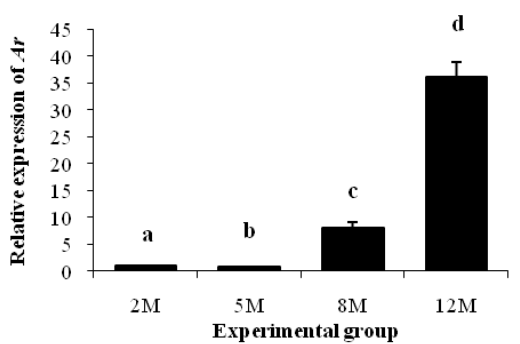

(C)

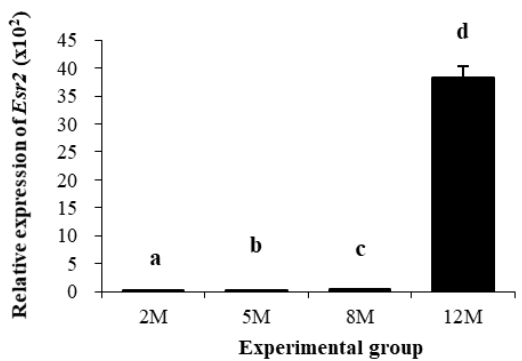

Fig. 2. Expression patterns of Srebp1, Ar, and Esr2 in the epididymal fat tissue of ERaKO mouse at different postnatal ages. The transcript levels of Srebp1 (A), $\operatorname{Ar}(\mathrm{B})$, and Esr2 (C) genes were normalized against its of $R n 18 \mathrm{~s}$, and relative expression ratios were calculated by $2^{-\Delta \Delta C t}$ method (Livak \& Schmittgen, 2001). Each value represents the mean \pm SEM of three to five mice. Lower cases on bars indicate statistical significances among experimental groups at $p<0.05$. M, months of postnatal age; Srebf1, sterol regulatory element binding transcription factor 1; Ar, androgen receptor; Esr2, estrogen receptor, beta; $18 \mathrm{~s}$ ribosomal RNA. ERaKO, estrogen receptor a knockout.

significantly different with that at 2 months of age (Fig. 3A). An increase of Pparg transcript level in the $\mathrm{ER} \alpha \mathrm{KO}$ epididymal fat was found at 8 months of age, and the expression of Pparg was further increased at 12 months of age (Fig. 3A). The expression of Fabp4 in the ER $\alpha$ KO epididymal fat was increased at 5 months of age, followed by further surge of Fabp 4 transcript level at 8 months of age (Fig. 3B). A huge rise of Fabp 4 transcript level was detected at 12 months of age (Fig. 3B).

The expression pattern of Dlk1 in the $\mathrm{ER} \alpha \mathrm{KO}$ epididymal fat during postnatal period was quite similar with its of Fabp4 (Fig. 3C). The transcript level of Dlk1 at 5 months of age was significantly higher than that at 2 months of age (Fig. 3C). The amount of Dlk1 mRNA in the $\mathrm{ER} \alpha \mathrm{KO}$ epididymal fat at 8 months of age was about 50 -folds greater than that at 5 months of age (Fig. 3C). Another surge of Dlk1 expression in the ER $\alpha$ KO epididymal fat was found at 12 months of age (Fig. 3C).

\section{Postnatal expression patterns of Fasn and $L p /$ in the epididymal fat pad of ER $\alpha \mathrm{KO}$ mouse}

The level of Fasn transcript in the ER $\alpha \mathrm{KO}$ epididymal fat at 5 months of age was significantly decreased, compared with that at 2 months of age (Fig. 4A). There was no statistical change on expression level of Fasn between 5 and 8 months of age, even though a surge of Fasn transcript level

(A)

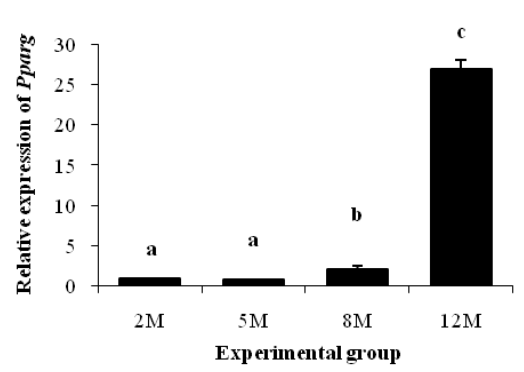

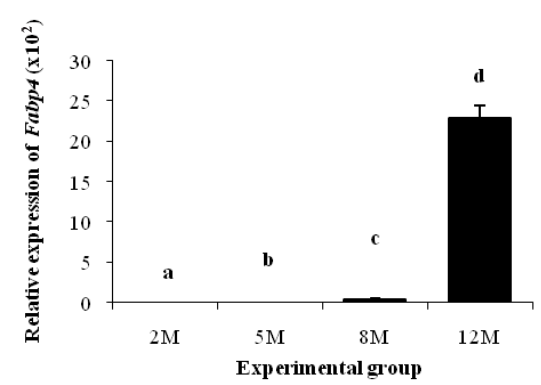

(C)

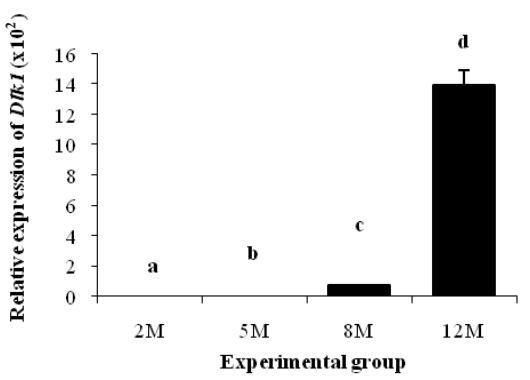

Fig. 3. Expression patterns of Pparg, Fabp4, and Dlk1 in the epididymal fat tissue of ERaKO mouse at different postnatal ages. The transcript levels of Pparg (A), Fabp4 (B), and Dkl1 (C) genes were normalized against its of Rn18s, and relative expression ratios were calculated by $2^{-\Delta \Lambda C t}$ method (Livak \& Schmittgen, 2001). Each value represents the mean \pm SEM of three to five mice. Lower cases on bars indicate statistical significances among experimental groups at $p<0.05$. M, months of postnatal age; Pparg, peroxisome proliferator-activated receptor, gamma; Fabp4, fatty acid binding protein 4; DIk1, delta like non-canonical Notch ligand 1; 18s ribosomal RNA. ERaKO, estrogen receptor a knockout. 
(A)

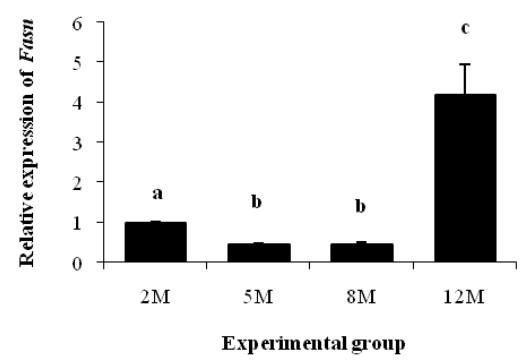

(B)

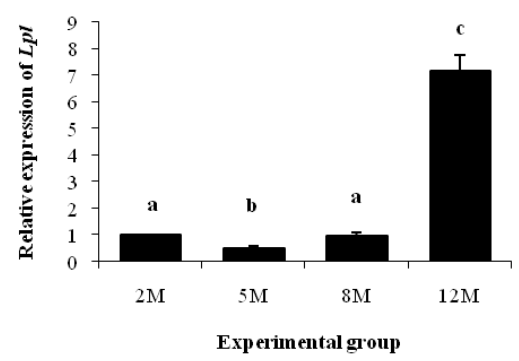

Fig. 4. Expression patterns of Fasn and $L p l$ in the epididymal fat tissue of ERaKO mouse at different postnatal ages. The transcript levels of Fasn (A) and $L p l(B)$ genes were normalized against its of Rn18s, and relative expression ratios were calculated by $2^{-\Delta \mathrm{CAt}}$ method (Livak \& Schmittgen, 2001). Each value represents the mean \pm SEM of three to five mice. Lower cases on bars indicate statistical significances among experimental groups at $p<0.05$. M, months of postnatal age; Fasn, fatty acid synthase; $L p l$, lipoprotein lipase; 18s ribosomal RNA. ERaKO, estrogen receptor a knockout.

was found at 12 months of age (Fig. 4A).

The $L p l$ transcript level in the $\mathrm{ER} \alpha \mathrm{KO}$ epididymal fat at 5 months of age was lower than that at 2 months of age (Fig. 4B). However, the level of $L p l \mathrm{mRNA}$ at 8 months of age was returned to that at 2 months of age, followed by the highest expression level of $L p l$ at 12 months of age (Fig. $4 \mathrm{~B})$.

\section{Postnatal expression patterns of Lep, Adipoq, and Retn in the epididymal fat pad of ER $\alpha$ KO mouse}

The transcript level of Lep was significantly increased at 5 months of age, compared with that at 2 months of age (Fig. 5A). However, the amount of Lep transcript in the ER $\alpha \mathrm{KO}$ epididymal fat was not changed until 12 months of age (Fig. $5 \mathrm{~A}$ ). On the other hand, there was no significant change of the Adipoq transcript level between 2 and 5 months of age, followed by about one-fold increase of Adipoq mRNA amount at 8 months of age (Fig. 5B). A tremendous increase of Adipoq transcript level was observed in the $\mathrm{ER} \alpha \mathrm{KO}$ epididymal fat at 12 months of age (Fig. $5 \mathrm{~B}$ ).

The expression pattern of Retn in the $\mathrm{ER} \alpha \mathrm{KO}$ epididymal fat during postnatal period is shown in Fig. 5C. The transcript level of Retn at 5 months of age was significantly decreased, compared with that at 2 months of age (Fig. 5C). There was no change of Retn transcript level between 5 and

(A)

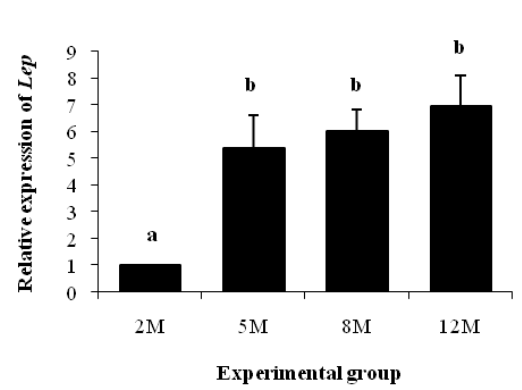

(B)

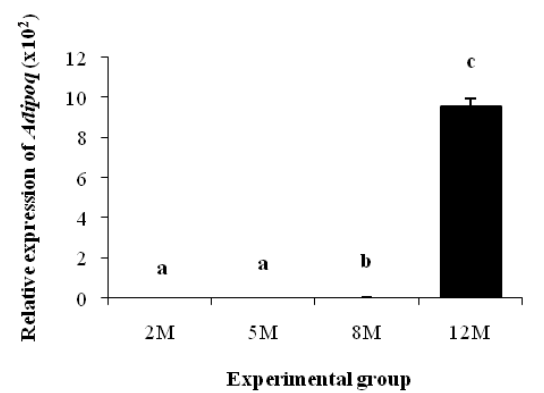

(C)

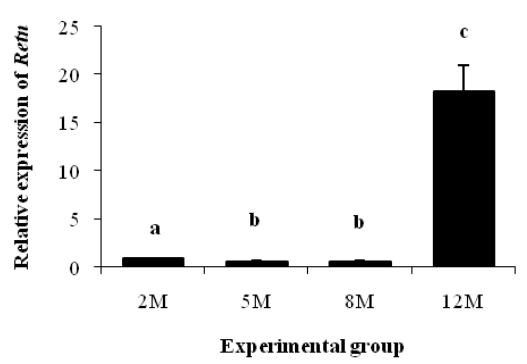

Fig. 5. Expression patterns of Lep, Adipoq, and Retn in the epididymal fat tissue of ERaKo mouse at different postnatal ages. The transcript levels of Lep (A), Adipoq (B), and Retn (C) genes were normalized against its of Rn18s, and relative expression ratios were calculated by $2^{-\Delta \Lambda C t}$ method (Livak \& Schmittgen, 2001). Each value represents the mean \pm SEM of three to five mice. Lower cases on bars indicate statistical significances among experimental groups at $p<0.05$. M, months of postnatal age; Lep, leptin; Adipoq, adiponectin; Retn, resistin; 18s ribosomal RNA. ERaKO, estrogen receptor a knockout. 
8 months of age, even though a clear surge of Retn expression was detected at 12 months of age (Fig. $5 \mathrm{C})$.

\section{DISCUSSION}

The expression of adipocyte development- and function-associated molecules in the ER $\alpha \mathrm{KO}$ epididymal fat tissue has been determined in the present research, presumably for the first time, to our knowledge. As anticipated, the expression of Esr1 was not detected at any postnatal age, indicating the exclusion of methodological errors derived from a real-time PCR analysis. Even though expression patterns of some molecules between 2 and 8 months of ages were different with those of other molecules, the expression levels of all other molecules examined here were generally increased with age and were the highest at 12 months of age, except Lep.

The postnatal epididymal fat contains not only lipid-filled fully differentiated adipocytes but also undifferentiated preadipocytes at unneglectable amount (Cleary et al., 1977). Thus, it is likely that the growth and extension of the epididymal fat during postnatal period are associated with the increased mature adipocyte number and size, as well as proliferation of preadipocyte and differentiation rate of preadipocyte into mature adipocyte at the early postnatal age. The differentiation of preadipocyte into adipocyte requires differential expression of numerous transcription factors and/or regulatory molecules (Niemelä et al., 2008; Mareno-Navarrete \& Fernández-Real, 2012). A decrease of Dlk1 expression is necessary to begin the adipogenesis and the accumulation of lipid droplets in the adipocyte (Niemelä et al., 2008; Mareno-Navarrete \& Fernández-Real, 2012). Expressional increases of Cebpa and Pparg lead to activation of adipocytespecific genes for terminal differentiation of preadipocyte, while Cebpb and Cebpg act on the early adipogenic induction of preadipocyte (Niemelä et al., 2008). Lipogenesis of adipocyte is stimulated by the action of Srebp1, and an induction of Fabp4 expression is observed during terminal differentiation of early adipocyte into fully-mature adipocyte (Niemelä et al., 2008). Even though mature adipocyte secretes soluble form of LPL, an increase of $L p l$ expression is found at the early stage of adipogenesis (Niemelä et al., 2008). The Lep and Adipoq, are kinds of adipokines, which are cytokines produced from adipocyte and play important functions for communication between adipocyte and target tissues, including brain, liver, immune system, and reproductive tissue (Fasshauer \& Blüher, 2015). In addition, it is known that Retn is a representative cytokine secreted from adipose tissue and involves in insulin resistance and inflammation (Fasshauer \& Blüher, 2015). Other than these factors, various adipogenic and antiadipogenic molecules participate in regulation of adipogenesis during the development of adipose tissue (Niemelä et al., 2008; Mareno-Navarrete \& Fernández-Real, 2012). Thus, it is important to understand how expression of these molecules involved in the control of adipogenesis is regulated.

Hormonal influence on adipocyte differentiation has been examined from a number of researches. The differentiation of adipocyte is stimulated by insulin-like growth factor 1 , glucocorticoids, and thyroid hormone (Niemelä et al., 2008; Mareno-Navarrete \& FernándezReal, 2012). These factors promote the adipogenesis by modulating expression of Cebpg, Pparg, and Cebpb, which are necessary for adipocyte differentiation (Niemelä et al., 2008). However, epidermal growth factor, tumor necrosis factor- $\alpha$, interleukin-1, and transforming growth factor are commonly known antiadipogenic factors, which suppress adipogenesis by affecting expression of Pparg and Cebpa and inhibiting activity of Pparg (Niemelä et al., 2008; Mareno-Navarrete \& Fernández-Real, 2012).

Other than peptide hormones affecting adipocyte differentiation, estrogen, a steroid hormone, 
has caught the attention due to its antiadipogenic and antilipogenic effects on the development of adipose tissue during postnatal period (Cooke $\&$ Naaz, 2004). As shown in the present and other researches, the epididymal fat possesses both $\mathrm{ER} \alpha$ and $\mathrm{ER} \beta$, indicating a direct effect of estrogen through functional ERs (Metz et al., 2016). In fact, a lack of functional $\mathrm{ER} \alpha$, as seen in $\mathrm{ER} \alpha \mathrm{KO}$ mouse, results in an increase of the epididymal fat mass (Heine et al., 2000). Similar findings have been observed at Cyp19 knockout (aromatase knockout, ARKO) mice, which do not produce estrogen (Jones et al., 2000). From these data, it is suggested that ER $\alpha$ plays an important role on differentiation and maturation of adipocyte in the epididymal fat. Our previous researches have shown expression patterns of several transcription factors involving in the regulation of adipogenesis and some secretory molecules from the epididymal fat tissue of WT mice during postnatal period (Lee, 2019; Lee \& Kim, 2019). However, these findings are not directly comparable with results acquired from the current research because of different experimental materials examined, a whole epididymal fat tissue in the present study vs. a separate part of epididymal fat tissue in the earlier researches. In spite of, the highest levels of Lep, Pparg, Lpl, Fabp4, Dlk1, Retn, Adipoq, and Fasn are observed in the distal epididymal fat of WT mouse (Lee \& Kim, 2019) and a whole epididymal fat of ER $\alpha \mathrm{KO}$ mouse at 12 months of postnatal age, while expression patterns of these molecules, except Pparg and Dlk1, in the proximal epididymal fat of WT mouse are quite different with those in $\mathrm{ER} \alpha \mathrm{KO}$ mouse. Based on these observations, it is speculated that regional difference of Esr1 expression level within the epididymal fat tissue could influence on differential expression of adipocyte maturation and differentiation-associated factors. Regional examination of the epididymal fat of $\mathrm{ER} \alpha \mathrm{KO}$ mouse would provide more detailed information about different expressional regulation of these molecules through functional $\operatorname{ER} \alpha$.

The ER $\alpha \mathrm{KO}$ mouse already has heavier epididymal fat weight than WT mouse at 30 days of postnatal age, and the degree of epididymal fat weight difference between $\mathrm{ER} \alpha \mathrm{KO}$ and WT mice becomes extended from about 1.6 times at 30 days to about 2.3 times at 270-360 days of age (Heine et al., 2000). In addition, adipocyte size and number in the epididymal fat of $\mathrm{ER} \alpha \mathrm{KO}$ mouse are bigger and larger than WT mouse at 180 days of age (Heine et al., 2000). Moreover, it is documented that estrogen through $\mathrm{ER} \alpha$ exerts its effects on adipose tissue by a decrease of lipogenesis rate accompanied with a reduction of $L p l$ expression, an increase of lipolysis, and stimulation of adipogenesis associated with an increase of adipocyte precursor proliferation (Cooke $\&$ Naaz, 2004). A lack of estrogen action through ER $\alpha$ results in an increase of size and number of adipocytes at adult and developmental stage, respectively (Cooke \& Naaz, 2004). Based on these observations, continuously increased expression of adipogenic factors and decreased expression of antiadipogenic factors have been expected in the $\mathrm{ER} \alpha \mathrm{KO}$ epididymal fat tissue. However, even though expression patterns of Cebpb and Fabp4 seem to follow our prospect, expression patterns of most molecules in $\mathrm{ER} \alpha \mathrm{KO}$ epididymal fat during postnatal period have not agreed with our expectation. A lack of functional $\mathrm{ER} \alpha$ from the beginning in the $\mathrm{ER} \alpha \mathrm{KO}$ mouse would be a reason to explain the difference between experimental data and our speculation. Despite, the current research has been recognized for the demonstration of the existence and expression patterns of various factors-associated with adipocyte in the $\mathrm{ER} \alpha \mathrm{KO}$ epididymal fat at different postnatal ages.

\section{REFERENCES}

Berry DC, Stenesen D, Zeve D, Graff JM (2013) The developmental origin of adipose tissue. Development 140:3939-3949.

Cleary MP, Greenwood MRC, Brasel JA (1977) A multifactor analysis of growth in the rat 
epididymal fat pad.J Nutr 107:1969-1974.

Cooke PS, Naaz A (2004) Role of estrogens in adipocyte development and function. Exp Biol Med 229:1127-1135.

Dieudonne MN, Pecquery R, Leneveu MC, Jaubert AM, Giudicelli Y (1995) Androgen receptors in cultured rat adipose precursor cells during proliferation and differentiation: regional specificities and regulation by testosterone. Endocrine 3:537-541.

Fasshauer M, Blüher M (2015) Adipokines in health and disease. Trends Pharmacol Sci 36:461470.

Gieske MC, Kim HJ, Legan SJ, Koo Y, Krust A, Chambon P, Ko CM (2008) Pituitary gonadotroph estrogen receptor-alpha is necessary for fertility in females. Endocrinology 149:20-27.

Gray JM, Wade GN (1980) Cytoplasmic estrogen, but not progestin, binding sites in male rat adipose tissues. Am J Physiol 239:E237-E241.

Han J, Lee JE, Jin J, Lim JS, Oh N, Kim K, Chang SI, Shibuya M, Kim H, Koh GY (2011) The spatiotemporal development of adipose tissue. Development 138:5027-5037.

Hausman DB, DiGirolamo M, Bartness TJ, Hausman GJ, Martin RJ (2001) The biology of white adipocyte proliferation. Obes Rev 2:239-254.

Heine PA, Taylor JA, Iwamoto GA, Lubahn DB, Cooke PS (2000) Increased adipose tissue in male and female estrogen receptor- $\alpha$ knockout mice. Proc Natl Acad Sci USA 97:1272912734.

Jones MEE, Thorburn AW, Britt KL, Hewitt KN, Wreford NG, Proietto J, Oz OK, Leury BJ, Robertson KM, Yao S, Simpson ER (2000) Aromatase-deficient (ArKO) mice have a phenotype of increased adiposity. Proc Natl Acad Sci USA 97:12735-12740.

Knittle JL, Hirsch J (1968) Effect of early nutrition on the development of rat epididymal fat pads: cellularity and metabolism.J Clin Invest 47:2091-2098.

Kõressaar T, Lepamets M, Kaplinski L, Raime K, Andreson R, Remm M (2018) Primer3_ masker: integrating masking of template sequence with primer design software. Bioinformatics 34:1937-1938.

Lee KH (2019) Postnatal expressional patterns of adipose-associated molecules in the mouse proximal epididymal fat. Dev Reprod 23:313-322.

Lee $\mathrm{KH}$ (2020) Expression of adipocyte-associated genes in the mouse tail epididymal fat at different postnatal ages. Dev Reprod 24:167-176.

Lee KH, Kim NH (2019) Differential expression of adipocyte-related molecules in the distal epididymal fat of mouse during postnatal period. Dev Reprod 23:213-221.

Livak KJ, Schmittgen TD. (2001) Analysis of relative gene expression data using real-time quantitative pcr and the $2^{-\Delta \Delta \mathrm{Ct}}$ method. Methods 25:402-408.

Mareno-Navarrete JM, Fernández-Real JM (2012) Adipcyte differentiation. In: Symonds ME (ed), Adipose Tissue Biology. Springer, New York, NY, pp 17-38.

Metz L, Gerbaix M, Masgrau A, Guillet C, Walrand S, Boisseau N, Boirie Y, Courteix D (2016) Nutritional and exercise interventions variably affect estrogen receptor expression in the adipose tissue of male rats. Nutr Res 36:280-289.

Niemelä S, Miettinen S, Sarkanen JR, Ashammakhi N (2008) Adipose tissue and adipocyte differentiation: molecular and cellular aspects and tissue engineering application. In: Ashammakhi N, Reis R, Chiellini F (eds), Topics in Tissue Engineering, Vol. 4, Oulu University, Oulu, Finland, pp 1-26.

Tirard J, Gout J, Lefrançois-Martinez AM, Martinez A, Begeot M, Naville D (2007) A novel inhibitory protein in adipose tissue, the aldo-keto reductase AKR1B7: its role in adipogenesis. Endocrinology 148:1996-2005. 